\title{
Major Transitions in Cuticular Hydrocarbon Expression Coincide with Sexual Maturity in a Blowfly (Diptera: Calliphoridae)
}

\author{
Nathan J. Butterworth ${ }^{1}$ • Falko P. Drijfhout ${ }^{2}$ • Phillip G. Byrne ${ }^{1}$ - Paul A. Keller ${ }^{3}$ - James F. Wallman ${ }^{1,4}$ \\ Received: 3 March 2020 / Revised: 10 June 2020 / Accepted: 17 June 2020 \\ (C) Springer Science+Business Media, LLC, part of Springer Nature 2020
}

\begin{abstract}
In many animals, there is a prolonged pre-reproductive period prior to sexual maturity. To avoid premature mating attempts, it is common for phenotypic changes to occur during this period that signal the onset of reproductive viability. Among the insects, pre-reproductive phases can last for up to $50 \%$ of the adult lifespan, but little is known about the accompanying phenotypic changes that signal sexual maturity. Contact pheromones such as cuticular hydrocarbons (CHCs) may fulfil this role, as they are known to change rapidly with age in many insects. Despite this, few studies have investigated CHC development in the context of sexual maturity or considered differences in CHC development between sexes. The blowflies (Diptera: Calliphoridae) provide an ideal system for such studies because CHCs are known to change rapidly with age and likely play an important role in sexual behaviour. As such, using the small hairy maggot blowfly Chrysomya varipes, we investigate whether there are age- and sexspecific changes in CHCs over the course of adult blowfly maturation. We show that: (1) major qualitative transitions in CHC expression coincide with the onset of sexual maturity and (2) these changes occur more slowly in females - in line with their extended pre-reproductive phase. We suggest that CHCs may play an important role in signalling sexual maturity in the small hairy maggot blowfly and that this species will likely serve as a useful model for understanding the complex ontogeny of cuticular hydrocarbon development in insects.
\end{abstract}

Keywords Maturation · Cuticular hydrocarbons · Development - Diptera - Sexual selection · Pheromone $\cdot$ Chemical communication

\section{Introduction}

Sexual maturation is a particularly important step in animal life history, the timing of which is dependent on a range of environmental and genetic factors (Bernardo 1993). While

Electronic supplementary material The online version of this article (https://doi.org/10.1007/s10886-020-01194-2) contains supplementary material, which is available to authorized users.

Nathan J. Butterworth nb187@uowmail.edu.au

1 Centre for Sustainable Ecosystem Solutions, School of Earth, Atmospheric and Life Sciences, University of Wollongong, Wollongong, NSW 2522, Australia

2 School of Chemical and Physical Sciences, Keele University, Keele, UK

3 School of Chemistry and Molecular Bioscience, Molecular Horizons, University of Wollongong and Illawarra Health and Medical Research Institute, Wollongong, Australia

4 School of Life Sciences, University of Technology Sydney, Ultimo, NSW 2007, Australia many animals are reproductively viable shortly after reaching adulthood, numerous species exhibit a substantial delay between the onset of adulthood and full sexual maturity. Examples include the prolonged pre-reproductive phases of corroboree frogs (three to five years) (McFadden et al. 2013) and female mosquitoes prior to a blood meal (O'Meara and Lounibos 1981). These pre-reproductive phases have likely evolved due to a variety of distinct selective pressures. Such pressures include reproductive resources being unpredictably scattered (Thornhill and Alcock 1983), time for acquisition of sufficient energy reserves prior to intrasexual conflicts (Campanella and Wolf 1974), costly development of ovaries or the production of spermatophores (Stay and Roth 1956), reduction of reactive oxygen species generation by slowing reproductive development (Guerra et al. 2012), or preventing close inbreeding between newly emerged adult relatives (by creating a reproductive barrier prior to dispersion) (Bukowski and Avilés 2002).

During this pre-reproductive adult phase, both sexes can be expected to have some way of signalling their sexual maturity to conspecifics to avoid costly and fruitless mating attempts. Thus, in many animals, the progression from pre-reproductive 
to sexually mature adult is often accompanied by changes in secondary sexual traits; such as the facial hair of humans (Dixson and Rantala 2016), the mane of lions (West and Packer 2002), and the antlers of reindeer (Leader-Williams 1979; Markusson and Folstad 1997). These traits often perform dual roles in sexual behaviour, potentially acting as honest signals of quality, while simultaneously advertising that an individual is sexually mature and ready to reproduce. In circumstances where these traits are not sexually dimorphic, there can instead be sex-specific differences in the rates at which they develop.

Within the insects, prolonged pre-reproductive adult phases are particularly common (Thornhill and Alcock 1983); lasting 2 to 14 days in female Diptera (Boyce 1934; Teskey 1969; Fowler 1973), 7 days in some male Lepidoptera (Scott 1973), and up to several weeks in some Odonata (Corbet 1980). While there are likely to be numerous phenotypic traits that develop during this prereproductive adult phase and signal sexual maturity (Arienti et al. 2010; Khan and Herberstein 2019), in most insect taxa it is unclear which traits act as such signals. One phenotypic trait that may fulfil this function are cuticular hydrocarbons (CHCs) - long-chain hydrocarbons expressed on the cuticle of all insects, which act as close-range pheromones in numerous species (Kuo et al. 2012). The pattern of hydrocarbons are known to change greatly during insect development, with stark age-related changes in compound composition and concentrations in several taxa (Apidae: Vernier et al. 2019; Cerambycidae: Brodie at al. 2012; Culicidae: Caputo et al. 2005; Desena et al. 1999; Drosophilidae: Jackson and Bartelt 1986; Muscidae: Adams et al. 1984; Tephritidae: Vaníčková et al. 2012; Vespidae: Panek et al. 2001, Neves et al. 2012). Additionally, these characteristic changes in $\mathrm{CHC}$ expression appear to be key drivers for the onset of sexual attraction, particularly in flies (Calliphoridae: Trabalon et al. 1988; Drosophilidae: Silhacek et al. 1972; Muscidae: Adams et al. 1984; Arienti et al. 2010).

Despite this, relatively few studies have considered how these developmental changes in $\mathrm{CHCs}$ progress during the pre-reproductive adult phase of insects, or whether the rates of CHC development differ between the sexes. It would be expected, however, that where $\mathrm{CHCs}$ play a role in signalling sexual maturity, any major changes in $\mathrm{CHC}$ expression should coincide approximately with the onset of sexual maturity. Indeed, this was highlighted by Arienti et al. (2010) who showed that the major female CHCs of Drosophila melanogaster were not expressed until the onset of sexual maturity ( $\sim 24 \mathrm{~h}$ after eclosion) and that only females with these compounds triggered all stages of male courtship (including mating attempts). In addition, in circumstances where the timing of sexual maturity differs substantially between the sexes, it might also be expected that the rates of $\mathrm{CHC}$ development will be sex-specific.
The blowflies (Diptera: Calliphoridae) provide an ideal system to investigate CHC development in the context of sexual maturation. Many species show a substantial delay in sexual maturation, whereby, following eclosion, males mature within two to four days (Bartell et al. 1969; Mackerras 1933). By contrast, females can take anywhere from 3 to 12 days to mature and often require a protein meal to complete ovarian development (Bartell et al. 1969; Browne et al. 1976; Laurence 1988; Mackerras 1933; Norris 1959). Additionally, a substantial body of work has shown that, as is the case in Drosophila melanogaster, CHCs change drastically over the lifespan of adult blowflies, often coinciding with the onset of sexual maturity (Bernhardt et al. 2017; Braga et al. 2016; Roux et al. 2008; Pechal et al. 2014; Trabalon et al. 1992). However, this work has taken place primarily in a forensic context, with little consideration given to the selective pressures driving the relationship between $\mathrm{CHC}$ development and sexual maturity. The present study addresses this knowledge gap using the small hairy maggot blowfly Chrysomya varipes as a model system. In this Australasian species, there is strong sexual selection by females (suggesting high costs associated with female mating), and male courtship behaviour is highly complex and stereotyped (Jones et al. 2014; Jones et al. 2017). Females exhibit a prolonged pre-reproductive adult phase, taking approximately seven days post-eclosion to become sexually receptive (Jones et al. 2014; Jones et al. 2017) in contrast to three to four days in males (personal observation). We expect that given the high costs associated with female mating, avoiding premature mating attempts by signalling sexual maturity is likely to be particularly important in this species. Subsequently, we predict that stark changes in $\mathrm{CHC}$ expression will coincide with sexual maturity in this blowfly and that rates of $\mathrm{CHC}$ development will be sex-specific, occurring more slowly in females and in line with the prolonged female pre-reproductive adult phase.

\section{Methods}

Insect Stocks Established F13 lines of Ch. varipes were provided with $100 \mathrm{~g}$ of kangaroo mince (held in a plastic weigh boat) as an oviposition medium. Once eggs were laid, the meat was removed and isolated in a plastic rearing container $(130 \times 190 \times$ $70 \mathrm{~mm}$ ) with a fine mesh top. The bottom of the container was covered with wheaten chaff as a pupariation material, and the weigh boat containing the larvae was placed atop the chaff. Extra kangaroo mince $(\sim 200 \mathrm{~g})$ was provided to the larvae to ensure that food was not limiting. Upon pupariation, 100 pupae were each transferred into a smaller plastic eclosion container $(60 \times 85 \times 50 \mathrm{~mm})$ with a fly mesh lid. Each individual was provided with a constant supply of granulated raw sugar and water delivered via a cotton dental roll serving as a wick. Flies were also provided with a small portion $(\sim 5 \mathrm{~g})$ of kangaroo 
mince as a food source for reproductive development. Within $24 \mathrm{~h}$ of eclosion, five individuals of each sex were removed and their CHCs extracted with hexane (thus constituting the 'Day 1' cohort). Subsequently, five individuals of each sex were taken at days 2, 3, 5, 7 and 11. Eleven days is the point at which all individuals were sexually mature and expected to exhibit adult cuticular profiles (Jones et al. 2017).

Chemical Analysis Cuticular hydrocarbons were extracted from five individual male and female flies at 1, 2, 3, 5, 7, and 11 days of age $(\mathrm{N}=60$ flies) by immersion in $100 \mu \mathrm{L}$ of $n$-hexane in a $300 \mu \mathrm{L}$ glass insert. Each fly was immersed for 5 min, gently vortexed once using an S.E.M. vortex mixer (Adelab Scientific, Australia) and then removed from the solution. Washed flies were inspected following extraction to ensure that no cuticular damage had occurred, which may have caused internal fluids to leak. Samples corresponding to each fly were stored at $-40{ }^{\circ} \mathrm{C}$ for up to 10 days. Prior to analysis, samples were evaporated with nitrogen and reconstituted in $20 \mu \mathrm{L}$ of hexane containing an internal standard (2 ppm pentadecane). A sample $(1 \mu \mathrm{L})$ of this $\mathrm{CHC}$ extract was analysed by gas chromatography coupled with mass spectrometry (GC-MS). The used instrument was an Agilent 7890 GC coupled with an Agilent 7000 Triple-Quad MS and an Agilent 7693 Autosampler fitted with an Rxi-5 ms column $(20 \mathrm{~m} \times 0.18 \mathrm{~mm}$ ID; d.f. $=0.18 \mu \mathrm{m})$. Helium was used as the carrier gas at a flow rate of $0.8 \mathrm{~mL} / \mathrm{min}$. The inlet temperature was set to $270{ }^{\circ} \mathrm{C}$ and injection was performed in splitless mode. The column was held isothermally at $50^{\circ} \mathrm{C}$ for $1 \mathrm{~min}$, then ramped at a rate of $40^{\circ} \mathrm{C} / \mathrm{min}$ to $180^{\circ} \mathrm{C}$, before ramping at $5{ }^{\circ} \mathrm{C} / \mathrm{min}$ to $300{ }^{\circ} \mathrm{C}$. The mass spectrometer was operated at $70 \mathrm{eV}$ with a source temperature of $280{ }^{\circ} \mathrm{C}$ and scanning was performed from $\mathrm{m} / \mathrm{z}, 40$ to 500 .

Pre-treatment of Data Peaks were selected between C21 and C40 and only those that occurred in at least three specimens were manually integrated using Masshunter qualitative analysis B06.00. Retention indices were calculated by comparing peak elution times to those of a C7-C40 alkane standard. Hydrocarbons were identified by analysis of their mass spectra, identification of diagnostic ions, and corroboration with Kovats indices as described by Carlson et al. (1998). Where possible, identified CHCs were also verified against published literature values (Moore et al. 2014; Lubanga et al. 2016). Peak areas from all flies were then aligned by their retention indices using R package 'GCalignR' (Ottensmann et al. 2018) and manually inspected to assure conformance.

Statistical Analysis To test whether quantitative differences in CHCs sufficiently discriminated ages, while also accounting for the effect of sex, Principal Component Analysis (PCA; type Pearson's correlation matrix) was performed on the absolute proportions of CHCs (Supplementary Material 1). This allowed stepwise selection of the most meaningful variables using the Kaiser-Meyer-Olkin (KMO) index (>0.70) (Kaiser 1974; Cerny and Kaiser 1977). A stepwise (forward; entry threshold: $\mathrm{p}=0.05$; removal threshold: $\mathrm{p}=0.10$ ) discriminant analysis (DA) was then performed using the selected CHCs as quantitative variables and age and sex as qualitative variables. Statistics were achieved using XLStat-Premium 2019.2.1.

\section{Results}

A total of 60 flies were analysed, with 80 unique compounds being identified across all samples (ranging from 21 to 35 carbon atoms in length). Profile composition changed greatly during adult maturation, with substantial qualitative and quantitative changes occurring between days 1 and 11 . In females, the greatest profile shifts were observed between days 3 and 5, whereas in males this occurred between days 2 and 3 (Fig. 1). Generally, all quantitative and qualitative changes in compounds were mirrored between the sexes, however these changes occurred at completely different rates - approximately two days slower in females, in line with the prolonged female pre-reproductive adult phase. Further, sex-specific differences in the number of expressed CHCs were observed. On the day of emergence, females expressed on average 69 $\mathrm{CHCs}$, whereas males expressed $70 \mathrm{CHCs}$. By 11 days of age females expressed on average $55 \mathrm{CHCs}$ and males expressed only $51 \mathrm{CHCs}$.

On average, the CHC profiles of younger flies consisted of high proportions of monomethylalkanes and dimethylalkanes, while the CHC profiles of older flies consisted of substantially reduced dimethylalkane proportions, and increased proportions of $n$-alkenes and $n$-alkanes (Fig. 2). A number of compounds that were not detected or expressed only in minor amounts upon eclosion, were expressed as highly predominant peaks at sexual maturity (11,13-DiMeC27, C27:1). In fact, several compounds increased substantially and linearly with age (C25, 9,11-DiMeC25, C26, C27:1), while several others decreased substantially and linearly (2MeC28, C29, 2,XDiMeC28, 9MeC29, 14MeC30). Interestingly, the expression of some compounds also changed in a non-linear fashion, with considerable variation between individuals; for example 2,6DiMeC26, C27 and 7MeC25, 7MeC27 (Supplementary Material 2). Broadly, it appears that during maturation there is also a major shift in the chain lengths of CHCs that are expressed, from longer chain hydrocarbons (C29 to C33) in young flies to shorter chain hydocarbons (C25 to $\mathrm{C} 28$ ) in sexually mature flies.

Regarding quantitative differences, 45 meaningful compounds were selected from the PCA based on the KMO index. At the end of the variable selection process, the global sample adequacy reached a KMO index of 0.797 , and the first two principal component axes explained $59.4 \%$ and $16.0 \%$ of the 

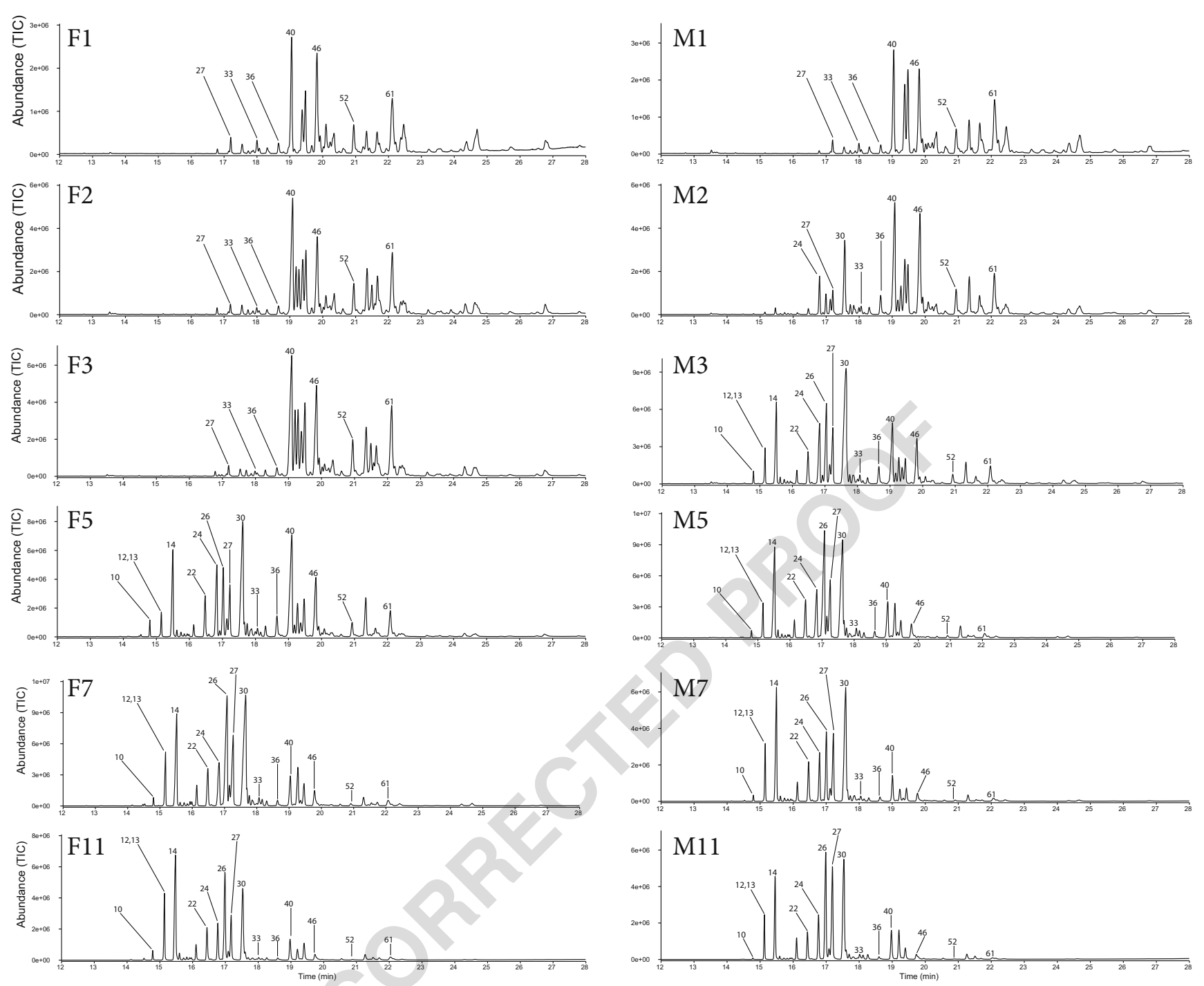

Fig. 1 Age-related changes in $\mathrm{CHC}$ profiles of adult Ch. varipes. A substantial shift from longer hydrocarbons to shorter hydrocarbons is seen around the onset of sexual maturity in both sexes. Total ion chromatograms of whole body extracts of one- to 11-day-old male (M)

total variation of the sample (eigenvalues $=26.73$ and 7.17). The first two axes of the stepwise discriminant analysis explained $57.6 \%$ and $14 \%$ of the total sample variation (eigenvalues 342.43 and 82.8 ). Further to this, discriminant analysis showed that based on the 45 selected CHCs, each combination of sex and age forms a unique cluster, and that the rate of development differs between the sexes; with males exhibiting quantitatively mature profiles by day 3 , while females do not reach this point until day 5 (Fig. 3). The greatest quantitative decreases were seen in $9 \mathrm{MeC} 29$, which comprised $16 \%$ of the female profile and $15 \%$ of the male profile at day 1 , but by day 11 constituted only $0.32 \%$ in females and $0.40 \%$ in males. Large decreases were also seen in $11,13 \mathrm{MeC} 31$ which made up $12 \%$ in females and $11 \%$ in males at day 1 , but only $0.87 \%$ in females and $0.53 \%$ in males by day 11 . Conversely, large increases were observed in $11,13 \mathrm{MeC} 27$ which was $1 \%$ in and female (F) Chrysomya varipes are presented. The figures have different values on the $\mathrm{Y}$-axes. Relative abundances and peak identifications are given in Supplementary Material 2

females and males at day 1 , and $16 \%$ in females and $22 \%$ in males by day 11 , and in $9,11 \mathrm{MeC} 25$ which was at $0.02 \%$ in females and $0.02 \%$ in males at day 1 , and $15 \%$ in females and $11 \%$ in males by day 11 (Supplementary Material 2). Notably, the $\mathrm{CHC}$ profiles of day 1 males and females were different, and the most major qualitative differences between the sexes were observed on day 3 (Figs. 1 and 3). The greatest qualitative change with age was seen in C27:1 which was not detectable in females or males at day 1 , but was at $13 \%$ in both females and males by day 11 .

\section{Discussion}

For many insects, a substantial proportion of adult life is spent in a pre-reproductive state, and it is expected that as 
J Chem Ecol

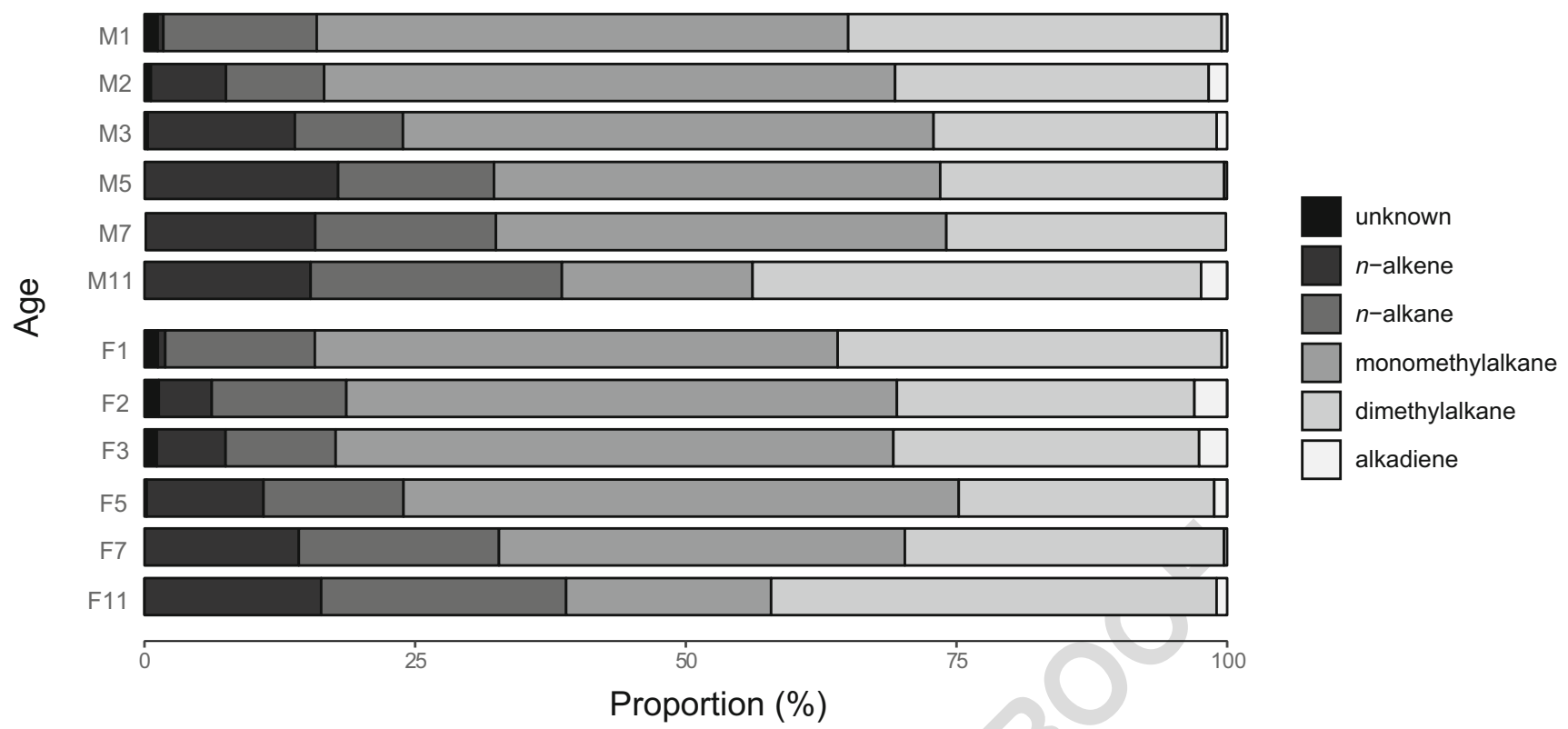

Fig. 2 Average proportions of CHC substance classes expressed by day 1 to 11-day-old adult male (M) and female (F) Chrysomya varipes. Generated with ggplot2 (Wickham et al. 2019) in R (R Core Team 2019). Edited with Adobe Illustrator

individuals develop there will be changes in phenotypic traits that signal sexual maturity and reproductive viability. Cuticular hydrocarbons may fulfil this role as they are widespread insect pheromones, and it is well known that their expression changes with age. Despite this knowledge, few studies have attempted to investigate how $\mathrm{CHC}$ expression coincides with sexual maturation or whether rates of $\mathrm{CHC}$ development are sex-specific. Here, using the small hairy maggot blowfly $C h$. varipes as a model, we demonstrate rapid qualitative and quantitative changes in $\mathrm{CHC}$ expression that

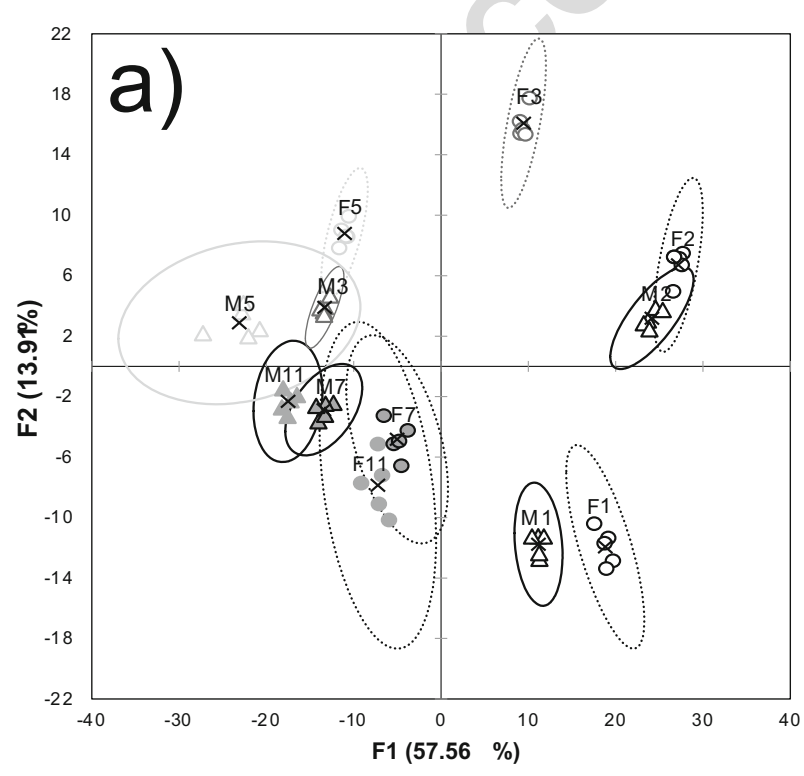

Fig. 3 Discriminant analysis of the cuticular hydrocarbon profiles of Chrysomya varipes. Plots represent (a) the clustering of sex and age groups (days 1, 2, 3, 5, 7 and 11) based on the first two discriminant coincide with the onset of sexual maturation and that male and female CHC development is sex-specific, occurring more slowly in females, in line with the prolonged female prereproductive adult phase in this species.

In total, we identified $80 \mathrm{CHCs}$ across all ages of $\mathrm{Ch}$. varipes; $69 \mathrm{CHCs}$ were expressed in pre-reproductive oneday-old flies and 55 were expressed in sexually mature 11day-old flies. The profiles of sexually mature adults align with our previous study on $C h$. varipes where we identified a total of 52 CHCs (Butterworth et al. 2018). However, comparing

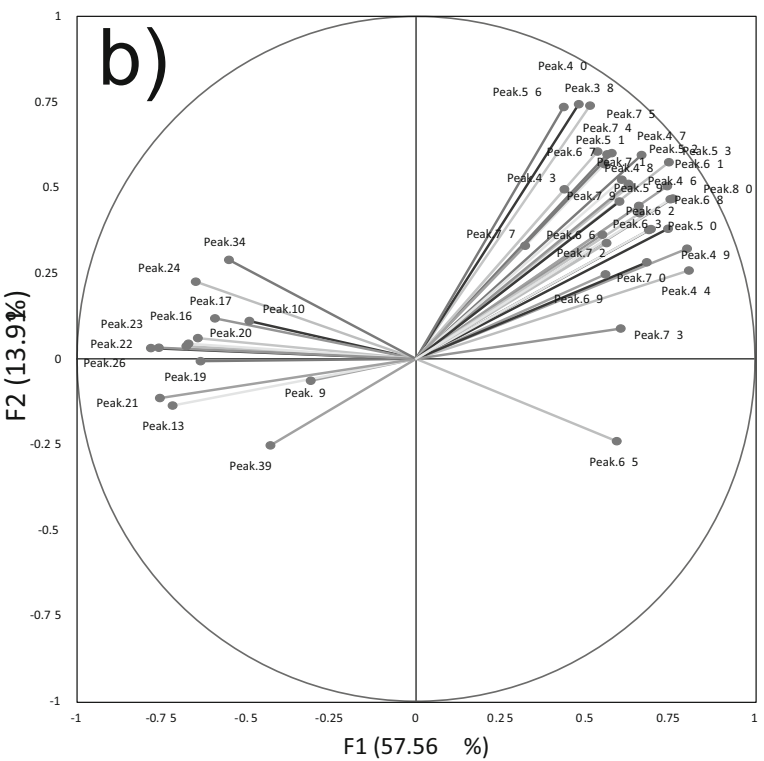

functions (b) the projection of variables onto the plane defined by the first two discriminant functions 
the profiles of 1- and 11-day-old flies suggests substantial age specific differences in the qualitative expression of CHCs, with $\sim 25$ CHCs produced in pre-reproductive adult flies that are not expressed in sexually mature adults. There were also numerous quantitative changes with age: the largest differences were seen in $9 \mathrm{MeC} 29$, which decreased from $15 \%$ in both sexes at day 1 to near undetectable levels by day 11 and $11,13 \mathrm{MeC} 31$, which decreased from $>10 \%$ in both sexes at day 1 to $0.9 \%$ in females and $0.5 \%$ in males by day 11 . Conversely both $9,11 \mathrm{MeC} 25$ and $\mathrm{C} 27: 1$ increased linearly with age from near undetectable levels in both sexes on day 1 , to $11-15 \%$ of the overall cuticular profile in both sexes by day 11. While these were the largest changes in CHC expression, they are not necessarily the most biologically important. In line with this, there were changes in the expression of almost every $\mathrm{CHC}$ in the profile with age, several of which were comparatively minor in magnitude but may nonetheless be biologically important. It is well known that minor quantitative changes in multiple $\mathrm{CHCs}$ can greatly alter the physiology of the cuticle - and it is often a complex mixture of CHCs that is involved in sexual recognition (Ferveur 2005; WickerThomas 2007).

Further to this, a general trend was observed whereby younger flies predominantly expressed longer hydrocarbons (C29 to C33), whereas older flies expressed shorter hydrocarbons (C25 to $\mathrm{C} 28)$. This shift towards shorter CHCs being expressed with increasing age, as well as an increase in monoenes (C27:1) and monomethylalkanes $(9,11 \mathrm{MeC} 25)$, mirrors age-related changes in the $\mathrm{CHC}$ profiles of numerous other insects (Wakonigg et al. 2000). This is particularly so in other schizophoran flies such as Anastrepha fraterculus, where shorter CHCs become more abundant with age, and the proportion of monoenes increases in both sexes (Vaníčková et al. 2012). In the housefly Musca domestica, females initially produce alkenes of $\mathrm{C} 27$ and longer, but switch to C23 alkenes after approximately $36 \mathrm{~h}$ (Adams et al. 1984). Likewise, in the blowfly, Calliphora vomitoria, there is a progressive change towards shorter chain lengths with age in both sexes (Trabalon et al. 1992), and in Drosophila species where shorter chain CHCs (C23 - C29) become more abundant with age, and in which monoenes increase rapidly after $12 \mathrm{~h}$ post-eclosion (Arienti et al. 2010; Jackson et al. 1986). This raises several questions: Is there an adaptive purpose for a shift from longer to shorter hydrocarbon chain lengths? How might this relate to the role of CHCs during sexual development?

While it is clear is that these changes coincide with the onset of sexual maturity in Ch. varipes, the selective pressures driving this relationship are unknown. Do age-related changes in CHCs serve an adaptive purpose? Alternatively, are they merely a consequence of the hormonal and ontogenetic changes in metabolism that occur with age? One answer to these questions comes from previous research in muscid and drosophilid flies. In both taxa, age-related changes in $\mathrm{CHC}$ expression can be perceived by adult conspecifics and are responsible for the onset of attraction at sexual maturity therefore signalling adult reproductive viability (Arienti et al. 2010; Silhacek et al. 1972). While the changes in CHC expression in these species may have (at some stage in their evolutionary history) been a side-effect of ontogenetic changes in metabolism, both studies provide evidence that the correlation between $\mathrm{CHC}$ expression and sexual maturity has likely been maintained by sexual selection. In M. domestica in particular, changes in $\mathrm{CHC}$ pheromones coincide directly with ovarian maturation and are regulated by ovarian produced ecdysone (Adams et al. 1984).

As such, we suggest that the correlation between CHC development and sexual maturation observed in Ch. varipes may fulfil the same purpose - to signal the onset of sexual maturity and female reproductive viability. This is especially so, considering that the changes stabilise around the age of sexual maturity, approximately 7 days in females (Jones et al. 2014) and that the rates of CHC development are slower in females, in line with females having a longer pre-reproductive phase than males. Furthermore, this function may be widespread in blowflies, as many species change $\mathrm{CHC}$ expression when transitioning from pre-reproductive to mature adults (Bernhardt et al. 2017). For example, the pre-reproductive adult phase of Chrysomya rufifacies lasts 7-10 days (Mackerras 1933), which correlates with the development of their adult CHC profile (Pechal et al. 2014). Additionally, C. vomitoria females take $120 \mathrm{~h}$ to become sexually mature, their CHC profiles stabilise after the same period, and this corresponds with the onset of male attraction (Trabalon et al. 1992). However, to support the claim that these CHCs signal sexual maturity in blowflies, behavioural bioassays are required. This could be achieved by masking the $\mathrm{CHCs}$ of prereproductive females (day 1 or 3) with $\mathrm{CHCs}$ from sexually mature females (day 7 or 9) and assessing whether this manipulation causes premature mating attempts by males.

While it is plausible that these age-related $\mathrm{CHC}$ transitions signal sexual maturity in blowflies, an important related consideration is why blowflies exhibit such prolonged prereproductive adult phases at all. Like any physiological trait, the rate of sexual maturation in adult insects is variable and subject to selection (Thornhill and Alcock 1983). One selective pressure that can cause such prolonged pre-reproductive phases is the high fitness cost of close inbreeding, as reported in the subsocial spider Anelosimus jucundus (Bukowski and Avilés 2002; Thornhill and Alcock 1983). The likelihood of close inbreeding is particularly high in insect species where adult emergence occurs synchronously and from the same resource, as is the case in many blowflies such as $C h$. varipes (pers obs.). By prolonging the pre-reproductive phase during the initial period of adult dispersal, the opportunities for sibling males and females to mate with each other shortly after 
emergence is limited. This reasoning may also explain differences in the timing of sexual maturation between the sexes. Importantly, this extended pre-reproductive period incurs selective pressure on any sexually mature individuals to recognise the reproductive status of potential mates that they encounter - as mating with pre-reproductive adults would incur high fitness costs to both parties. This likely explains the evolution of phenotypic traits that signal sexual maturity, such as CHCs.

However, a second key consideration is that the correlation between $\mathrm{CHC}$ development and sexual maturity may be the result of ecological selection, rather than sexual selection. For instance, it is well known that $\mathrm{CHCs}$ are heavily involved in desiccation tolerance (Chung and Carroll 2015; Sprenger and Menzel 2020). It is likely that the ecological pressures experienced by the larvae differ substantially from those experienced by the adults, particularly in regard to desiccation stress. It is probable that these differences in ecology between larval and adult stages have driven the evolution of larval- and adultspecific CHC profiles. In fact, it is well established that CHC expression changes greatly between larval, pupal, and adult stages in several blowfly species (Roux et al. 2008). It may, therefore, be the case that the suite of $\mathrm{CHCs}$ required during the larval stage constrains the types of CHCs that can be expressed during adult eclosion. Subsequently, the transition from larval to adult $\mathrm{CHC}$ profile may be a gradual process, as alterations in $\mathrm{CHC}$ expression and the synthesis of new CHCs (such as $\mathrm{C} 27: 1$ in $C h$. varipes) require numerous changes to gene expression and metabolic pathways (Chung and Carroll 2015). Thus, the prolonged rate of $\mathrm{CHC}$ development may simply be an artifact of the rate at which these biochemical processes can proceed.

If the speed of $\mathrm{CHC}$ development was only limited by metabolism and solely related to the role of CHCs in preventing desiccation, it is still unclear why $\mathrm{CHC}$ maturation would coincide so closely with sexual maturity and take as long as 11 days in Ch. varipes. Individuals of this species become highly active and disperse within $\sim 48 \mathrm{~h}$ of eclosion (Norris 1959), at which point flies without a mature CHC profile would be at severe risk of desiccation. It might, therefore, be expected that to prevent desiccation, ecological selection would drive $\mathrm{CHC}$ profiles to mature as quickly as possible. Furthermore, it is known that the $\mathrm{CHC}$ profiles of Drosophila species mature in $\sim 48 \mathrm{~h}$ (Arienti et al. 2010) and males of the blowfly $C$. vomitoria in $\sim 48 \mathrm{~h}$ (Trabalon et al. 1992). As such, there is no clear physiological reason for $\mathrm{CHC}$ development being so prolonged in Ch. varipes. To further ascertain the roles of ecological and sexual selection in maintaining the relationship between $\mathrm{CHC}$ development and sexual maturity, there is a need to assess the biochemical and genetic underpinnings of $\mathrm{CHC}$ development in species such as Ch. varipes in comparison to other blowflies, such as C. vomitoria, which show more rapid $\mathrm{CHC}$ development.
Lastly, the different rates of $\mathrm{CHC}$ development between the sexes are most likely due to inherent ontogenetic and hormonal differences; male flies tend to reach sexual maturity earlier than females (Arienti et al. 2010; Mackerras 1933). However, it may also be explained by ecological selection; it is possible that one sex disperses earlier or over greater distances in search of reproductive resources or mates. Subsequently, CHCs may have evolved to develop quicker in that sex in order to accommodate earlier exposure to desiccation stress during dispersal. A fascinating example of such environmentally driven sexual dimorphism is seen in Habronattus jumping spiders, where male-specific body colouration occurs as an anti-predator adaptation in response to males having increased activity levels and a higher resulting threat of predation during mate-searching (Taylor et al. 2019).

To summarise, we report that the development of CHCs in Ch. varipes is substantially delayed following adult eclosion and that the major changes in adult $\mathrm{CHC}$ expression coincide with the onset of sexual maturity, which differs between the sexes. In addition, in line with many other insect species, there is a negative relationship between increasing adult age and the chain length of expressed CHCs. However, it is unclear whether these patterns are the result of ecological or sexual selection or simply an inherent effect of ontogenetic hormonal and metabolic changes. Additional behavioural bioassays could definitely conclude that these $\mathrm{CHC}$ changes signal sexual maturity. Much would be gained from also explicitly measuring how $\mathrm{CHC}$ expression changes in line with development of male and female reproductive organs, and how this corresponds with the onset of reproductive viability. Such further research in Ch. varipes, and in other insects, will serve to unravel the role CHCs play in signalling sexual maturity. Overall, the age-related changes we report in $C h$. varipes are some of the most striking known examples of shifts in adult CHC profiles among insects, and this species will likely serve as an ideal model for unravelling the role of these complex traits in insect sexual behavior.

Acknowledgements We thank Claude Everaerts for his help with statistical analysis. We also acknowledge financial assistance towards this work from UOW's Centre for Sustainable Ecosystem Solutions.

Author Contributions Nathan J. Butterworth: Study conceptualisation, data acquisition, data analysis, manuscript preparation.

James F. Wallman: Contributed to study conceptualisation and manuscript preparation.

Falko P. Drijfhout: Assisted with data analysis, identified cuticular hydrocarbons from mass spectra.

Paul A. Keller: Contributed to study conceptualisation and manuscript preparation.

Phillip G. Byrne: Contributed to study conceptualisation and manuscript preparation.

Data Availability All data will be made available as supplementary material upon publication. 


\section{Compliance with Ethical Standards}

Conflicts of Interest The authors have no conflict of interest to declare.

Code Availability Not applicable.

\section{References}

Adams TS, Dillwith JW, Blomquist GJ (1984) The role of 20hydroxyecdysone in housefly sex pheromone biosynthesis. J Insect Physiol 30:287-294

Arienti M, Antony C, Wicker-Thomas C, Delbecque J-P, Jallon J-M (2010) Ontogeny of Drosophila melanogaster female sex-appeal and cuticular hydrocarbons. Integr Zool 5:272-282. https://doi.org/ 10.1111/j.1749-4877.2010.00213.x

Bartell RJ, Shorey HH, Barton Browne L (1969) Pheromonal stimulation of the sexual activity of males of the sheep blowfly Lucilia cuprina (Calliphoridae) by the female. Anim Behav 17:576-585. https://doi. org/10.1016/0003-3472(69)90166-3

Bernardo J (1993) Determinants of maturation in animals. Trends Ecol Evol 8:166-173. https://doi.org/10.1016/0169-5347(93)90142-C

Bernhardt V, Pogoda W, Verhoff MA, Toennes SW, Amendt J (2017) Estimating the age of the adult stages of the blow flies Lucilia sericata and Calliphora vicina (Diptera: Calliphoridae) by means of the cuticular hydrocarbon $n$-pentacosane. Sci Justice 57:361-365. https://doi.org/10.1016/j.scijus.2017.04.007

Boyce A (1934) Bionomics of the walnut husk fly\&nbsp;Rhagoletis completa. Hilgardia 8:363-579. https://doi.org/10.3733/hilg. v08n11p363

Brodie BS, Wickham JD, Teale SA (2012) The effect of sex and maturation on cuticular semiochemicals in Monochamus scutellatus (Coleoptera: Cerambycidae). Can Entomol 144:801-808. https:// doi.org/10.4039/tce.2012.82

Browne LB, Bartell RJ, van Gerwen ACM, Lawrence LA (1976) Relationship between protein ingestion and sexual receptivity in females of the Australian sheep blowfly Lucilia cuprina. Physiol Entomol 1:235-240. https://doi.org/10.1111/j.1365-3032.1976. tb00969.x

Bukowski TC, Avilés L (2002) Asynchronous maturation of the sexes may limit close inbreeding in a subsocial spider. Can J Zool 80:193198. https://doi.org/10.1139/z01-220

Butterworth NJ, Byrne PG, Keller PA, Wallman JF (2018) Body odor and sex: Do cuticular hydrocarbons facilitate sexual attraction in the small hairy maggot blowfly? J Chem Ecol 44:248-256. https://doi. org/10.1007/s10886-018-0943-3

Caputo B, Dani FR, Horne GL, Petrarca VP, Turillazzi S, Coluzzi M, Priestman AA, della Torre A (2005) Identification and composition of cuticular hydrocarbons of the major Afrotropical malaria vector Anopheles gambiae s.s. (Diptera: Culicidae): analysis of sexual dimorphism and age-related changes. J Mass Spectrom 40:15951604. https://doi.org/10.1002/jms. 961

Campanella PJ, Wolf LL (1974) Temporal leks as a mating system in a temperate zone dragonfly (Odonata: Anisoptera) I: Plathemis lydia (Drury). Behaviour 51:49-87. https://doi.org/10.1163/ $156853974 X 00147$

Carlson DA, Bernier UR, Sutton BD (1998) Elution patterns from capillary GC for methyl-branched alkanes. J Chem Ecol 24:1845-1865

Cerny CA, Kaiser HF (1977) A study of a measure of sampling adequacy for factor-analytic correlation matrices. Multivar Behav Res 12:4347

Chung H, Carroll SB (2015) Wax, sex and the origin of species: Dual roles of insect cuticular hydrocarbons in adaptation and mating. BioEssays 37:822-830. https://doi.org/10.1002/bies.201500014
Corbet PS (1980) Biology of Odonata. Annu Rev Entomol 25:189-217. https://doi.org/10.1146/annurev.en.25.010180.001201

Desena ML, Edman JD, Clark JM, Symington SB, Scott TW (1999) Aedes aegypti (Diptera: Culicidae) age determination by cuticular hydrocarbon analysis of female legs. J Med Entomol 36:824-830. https://doi.org/10.1093/jmedent/36.6.824

Dixson BJW, Rantala MJ (2016) The role of facial and body hair distribution in women's judgments of men's sexual attractiveness. Arch Sex Behav 45:877-889. https://doi.org/10.1007/s10508-015-0588-Z

Ferveur J (2005) Cuticular hydrocarbons: Their evolution and roles in Drosophila pheromonal communication. Behav Genet 35:279 295. https://doi.org/10.1007/s10519-005-3220-5

Fowler GL (1973) Some aspects of the reproductive biology of Drosophila: Sperm transfer, sperm storage, and sperm utilization. Adv Genet 17:293-360. https://doi.org/10.1016/S0065-2660(08) 60173-X

Guerra C, Zenteno-Savín T, Maeda-Martínez AN, Philipp EER, Abele D (2012) Changes in oxidative stress parameters in relation to age, growth and reproduction in the short-lived catarina scallop Argopecten ventricosus reared in its natural environment. Comp Biochem Phys A 162:421-430. https://doi.org/10.1016/j.cbpa. 2012.04.018

Jackson LL, Bartelt RJ (1986) Cuticular hydrocarbons of Drosophila virilis: comparison by age and sex. Insect Biochem 16:433-439. https://doi.org/10.1016/0020-1790(86)90056-9

Jones SD, Byrne PG, Wallman JF (2014) Mating success is predicted by the interplay between multiple male and female traits in the small hairy maggot blowfly. Anim Behav 97:193-200. https://doi.org/10. 1016/j.anbehav.2014.09.022

Jones SD, Byrne PG, Wallman JF (2017) Exploring the influence of individual courtship behaviors on male mating success in a blow fly. J Insect Behav 30:528-543. https://doi.org/10.1007/s10905017-9633-1

Kaiser H (1974) An index of factor simplicity. Psychometrika 39:31-36

Khan MK, Herberstein ME (2019) Ontogenetic colour change signals sexual maturity in a non-territorial damselfly. Ethology 126:51-58. https://doi.org/10.1111/eth.12959

Kuo T-H, Yew JY, Fedina TY, Dreisewerd K, Dierick HA, Pletcher SD (2012) Aging modulates cuticular hydrocarbons and sexual attractiveness in Drosophila melanogaster. J Exp Biol 215:814-821. https://doi.org/10.1242/jeb.064980

Laurence BR (1988) The tropical African latrine blowfly, Chrysomya putoria (Wiedemann). Med Vet Entomol 2:285-291. https://doi. org/10.1111/j.1365-2915.1988.tb00197.x

Leader-Williams N (1979) Age-related changes in the testicular and antler cycles of reindeer,\&nbsp; Rangifer tarandus. Reproduction 57: 117-126. https://doi.org/10.1530/jrf.0.0570117

Lubanga UK, Drijfhout FP, Farnier K, Steinbauer MJ (2016) The long and short of mate attraction in a psylloid: do semiochemicals mediate mating in Aacanthocnema dobsoni Froggatt? J Chem Ecol 42: $163-172$

Mackerras MJ (1933) Observations on the life-histories, nutritional requirements and fecundity of blowflies. Bull Entomol Res 24:353362. https://doi.org/10.1017/S0007485300031680

Markusson E, Folstad I (1997) Reindeer antlers: visual indicators of individual quality? Oecologia 110:501-507. https://doi.org/10.1007/ s004420050186

McFadden M, Hobbs R, Marantelli G, Harlow P, Banks C, Hunter D (2013) Captive management and reproduction of the critically endangered southern Corroboree frog (Pseudophryne corroboree) at Taronga and Melbourne Zoos. Amphib Reptile Conse 5:70-87

Moore HE, Adam CD, Drijfhout FP (2014) Identifying 1st instar larvae for three forensically important blowfly species using "fingerprint" cuticular hydrocarbon analysis. Forensic Sci Int 240:48-53

Neves E, Andrade L, Súarez Y, Lima S, Antonialli-Junior W (2012) Agerelated changes in the surface pheromones of the wasp 
643
Mischocyttarus consimilis (Hymenoptera: Vespidae). Genet Mol Res 11:1891-1898. https://doi.org/10.4238/2012.July.19.8

Norris KR (1959) The ecology of sheep blowflies in Australia. Biogeography and Ecology in Australia. Springer Netherlands, Dordrecht, pp 514-544. https://doi.org/10.1007/978-94-017-6295332

O'Meara GF, Lounibos LP (1981) Reproductive maturation in the pitcher-plant mosquito,\&nbsp;Wyeomyia smithii. Physiol Entomol 6:437-443. https://doi.org/10.1111/j.1365-3032.1981.tb00659.x

Ottensmann M, Stoffel MA, Nichols HJ, Hoffman JI (2018) GCalignR: An $\mathrm{R}$ package for aligning gas-chromatography data for ecological and evolutionary studies. PLoS One 13:e0198311. https://doi.org/ 10.1371/journal.pone.0198311

Panek LM, Gamboa GJ, Espelie KE (2001) The effect of a wasp's age on its cuticular hydrocarbon profile and its tolerance by nestmate and non-nestmate conspecifics (Polistes fuscatus, Hymenoptera: Vespidae). Ethology 107:55-63. https://doi.org/10.1046/j.14390310.2001.00633.x

Pechal JL, Moore H, Drijfhout F, Benbow ME (2014) Hydrocarbon profiles throughout adult Calliphoridae aging: A promising tool for forensic entomology. Forensic Sci Int 245:65-71. https://doi.org/ 10.1016/j.forsciint.2014.10.019

R Core Team (2019) R: A language and environment for statistical computing. R Foundation for Statistical Computing, Vienna. https:// www.R-project.org/

Roux O, Gers C, Legal L (2008) Ontogenetic study of three Calliphoridae of forensic importance through cuticular hydrocarbon analysis. Med Vet Entomol 22:309-317. https://doi.org/10.1111/j.1365-2915. 2008.00752.x

Silhacek D, Carlson D, Mayer M, James J (1972) Composition and sex attractancy of cuticular hydrocarbons from houseflies: Effects of age, sex, and mating. J Insect Physiol 18:347-354. https://doi.org/ 10.1016/0022-1910(72)90133-3

Sprenger PP, Menzel F (2020) Cuticular hydrocarbons in ants (Hymenoptera: Formicidae) and other insects: how and why they differ among individuals, colonies, and species. Myrmecol News 30:1-26. https://doi.org/10.25849/myrmecol.news.030:013
Stay B, Roth LM (1956) The reproductive behavior of Diploptera punctata (Blattaria: Diplopteridae). Proceedings of the 10th International Congress of Entomology. pp 547-552

Taylor LA, Cook C, McGraw KJ (2019) Variation in activity rates may explain sex-specific dorsal color patterns in Habronattus jumping spiders. PLoS One 14:e0223015. https://doi.org/10.1371/journal. pone. 0223015

Teskey HJ (1969) On the behavior and ecology of the face fly, Musca autumnalis (Diptera: Muscidae). Can Entomol 101:561-576. https://doi.org/10.4039/Ent101561-6

Thornhill R, Alcock J (1983) The evolution of insect mating systems. Harvard University Press, Cambridge

Trabalon M, Campan M, Clement J-L, Lange C, Miquel M-T (1992) Cuticular hydrocarbons of Calliphora vomitoria (Diptera): Relation to age and sex. Gen Comp Endocr 85:208-216. https:// doi.org/10.1016/0016-6480(92)90004-4

Trabalon M, Campan M, Clément J-L, Thon B, Lange C, Lefevre J (1988) Changes in cuticular hydrocarbon composition in relation to age and sexual behavior in the female Calliphora vomitoria (Diptera). Behav Process 17:107-115. https://doi.org/10.1016/ 0376-6357(88)90029-0

Vaníčková L et al (2012) Cuticular hydrocarbons of the South American fruit fly Anastrepha fraterculus: Variability with sex and age. J Chem Ecol 38:1133-1142. https://doi.org/10.1007/s10886-0120177-8

Vernier CL, Krupp JJ, Marcus K, Hefetz A, Levine JD, Ben-Shahar Y (2019) The cuticular hydrocarbon profiles of honey bee workers develop via a socially-modulated innate process. eLife 8:e41855. https://doi.org/10.7554/eLife.41855

Wakonigg G, Eveleigh L, Arnold G, Crailsheim K (2000) Cuticular hydrocarbon profiles reveal age-related changes in honey bee drones (Apis mellifera carnica). J Apicult Res 39:137-141. https://doi.org/ 10.1080/00218839.2000.11101033

West PM, Packer C (2002) Sexual selection, temperature, and the lion's mane. Science 297:1339. https://doi.org/10.1126/science.1073257

Wicker-Thomas C (2007) Pheromonal communication involved in courtship behavior in Diptera. J Insect Physiol 53:1089-1100. https://doi. org/10.1016/j.jinsphys.2007.07.003
680 


\section{AUTHOR QUERIES}

AUTHOR PLEASE ANSWER ALL QUERIES.

Q1. The citation "Stay and Roth 1958" has been changed to "Stay and Roth 1956" to match the author name/date in the reference list. Please check here and in subsequent occurrences, and correct if necessary.

Q2. Reference (Scott 1973) was mentioned in the manuscript; however, this was not included in the reference list. As a rule, all mentioned references should be present in the reference list. Please provide the reference details to be inserted in the reference list.

Q3. Reference (Braga et al. 2016) was mentioned in the manuscript; however, this was not included in the reference list. As a rule, all mentioned references should be present in the reference list. Please provide the reference details to be inserted in the reference list.

Q4. Reference (Jackson et al. 1986) was mentioned in the manuscript; however, this was not included in the reference list. As a rule, all mentioned references should be present in the reference list. Please provide the reference details to be inserted in the reference list. 